\title{
STRUCTURAL CHANGES AND REGIONAL MODELS OF AGRICULTURE
}

\author{
J. Doitchinova* \\ University of National and World Economy, Sofia, Bulgaria
}

\begin{abstract}
More than 10 years of Bulgarian membership in the European Union has resulted in significant changes not only in the product and organizational structures of the agrarian sector. These changes take place at different speed and form new models of agriculture by country. The purpose of the article is to analyze the regional changes in the product and organizational structures and to assess the characteristics of the emerging agricultural models in the northern and southern planning regions of Bulgaria.

The thesis of the article is that, regardless of the unidirection of the changes, the agrarian identity of the regions affects their speed and their characteristics.

The methdological approach is based on the assessment of the changes in product and organizational structures and their impact on the development of the regions. Subject of the research is the agrarian sector in the planning regions in our country. Conclusions were made for the consequences of changes in the importance of agriculture for the regional economy, their environmental impacts, income from farming, jobs, changes in the population, etc. The characteristics of agricultural models are described and guidelines and possibilities for their adaptation and development of the regional agricultural production potential were developed.
\end{abstract}

Key words: regional models of agriculture, structural changes,

\section{INTRODUCTION}

Agriculture has always developed in the rural areas, having varied impacts in terms of content (economic, social, environmental, etc.) and direction (positive and negative). Historically, it has shaped the landscape, as well as the ways of using the main local natural resources and the consequences for the qualities of the environmental factors.

At the same time, the territory of the agricultural land with its numerous charachteristic, determines the possibilities and the way of its development. The latter is reinforced in periods when along with the negative changes in the factors of the evnviroment and the decrease of natural and other recources, the quality requirements of the manufactured products increase.

The model of agriculture at the end of the 20th century is based on the productive agriculture regime. Its characteristics are one of the main

\footnotetext{
*Correspondence to: Julia Doitchinova: Phone + 359888711815; E-mail: juliadoj@unwe.bg
}

reasons for the negative trends in socioeconomic, ecological, demographic and others. processes in rural areas. More and more authors and institutions argue that "the rapid pace of concentration of agricultural production and the increasing polarization of agricultural structures led to significant problems in both intensive farming areas and disadvantaged areas" $(1,2)$. A large number of authors (3-5), who analyzed and periodically evaluated this problem for several decades, argued that the concentration of production and well-being in some regions and farms contradicts to the goal of a more balanced overall development since it is directly linked with the marginalization of other regions and farms. The EU Common Agricultural Policy has also a major impact on production patterns and has contributed to dramatic structural changes in a number of new accessd countries (6).

These processes in full-scale also apply to our country where the restructuring processes are markedly dynamic. The number of farms is now 201 thousand (2016) and is rapidly 
decreasing (for only 10 years more than 2.45 times compared to 2007), but the speed of these changes is different.

The purpose of the article is to analyze the regional changes in the product and organizational structures and to assess the characteristics of the emerging agricultural models in the Northern and Southern planning regions of Bulgaria.

\section{METODOLOGY}

During the period of Bulgaria's EU membership, the economic importance of the agricultural sector in the Bulgarian economy stabilized (4.7-4.8\%). The share of employed in total employment remains $17,7 \%$ (2018), with very high relative share $(84.1 \%)$ of selfemployed (7).

The focus of the survey is on the regional differences in agricultural models and the consequences for the rural region. The subject of the analysis are the characteristics of agriculture in the planning regions and the changes during the years of membership of our country in the EU. The application of the CAP activates product structuring processes. Not least is the impact of the introduction of a number of regulations and requirements on the conditions of plant growing and animal breeding, which also contributed to the significant changes in the organizational structures, and hence on the socio-economic indicators of the rural areas. As shown in Figure 1, the effects on rural areas from product and structural changes in the agrarian sector are sought.
By regions of the country there are differences in the economic importance of agriculture and the speed of changes. The figures for a fiveyear period (2013-2017) show that in the regions - the Northwest and North Central regions, agriculture occupy a share of over $10 \%$, while in other regions it renges $6-8 \%$ (Figure 2). Even more significant are the differences at district level - for 2017 they are between $22.9 \%$ for Silistra district to $2.97 \%$ for Varna district.

\section{CHANGES IN PRODUCT STRUCTURE}

During the first programming period the product changes continued in Bulgarian agriculture. There is an increase in the value of production mainly at the expense of plant production. This led to a significant reduction in the importance of livestock products. If in 2007 the ratio of gross production from plant and animal husbandry is 55 to 45, then in 2017 it will reach 77 to 23 .

The resulting production structure can also be compared with the EU average indicators. Bulgaria has and uses less than $4 \%$ of EU land resources but produces just under 1\% of GVA. The gross added value per unit of agricultural land in Bulgaria is 300 euro / ha at an EC average of 880 euro / ha (8).

The analysis of the product structure shows the large differences in the six regions. It ranges from 6.6 to 1 in the North-West region to 1.75 to 1 in the South Central and South-West regions.

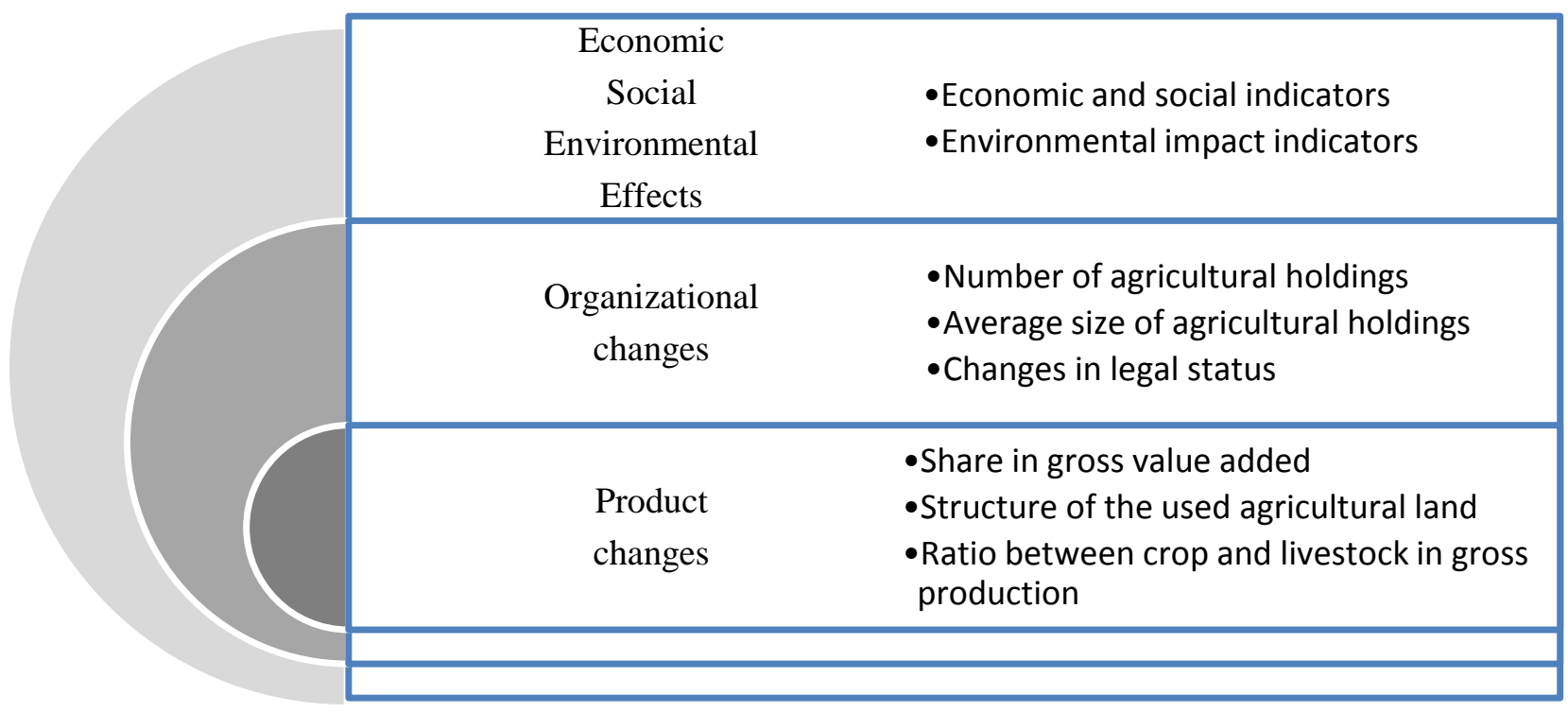

Figure 1. Metodological framework 


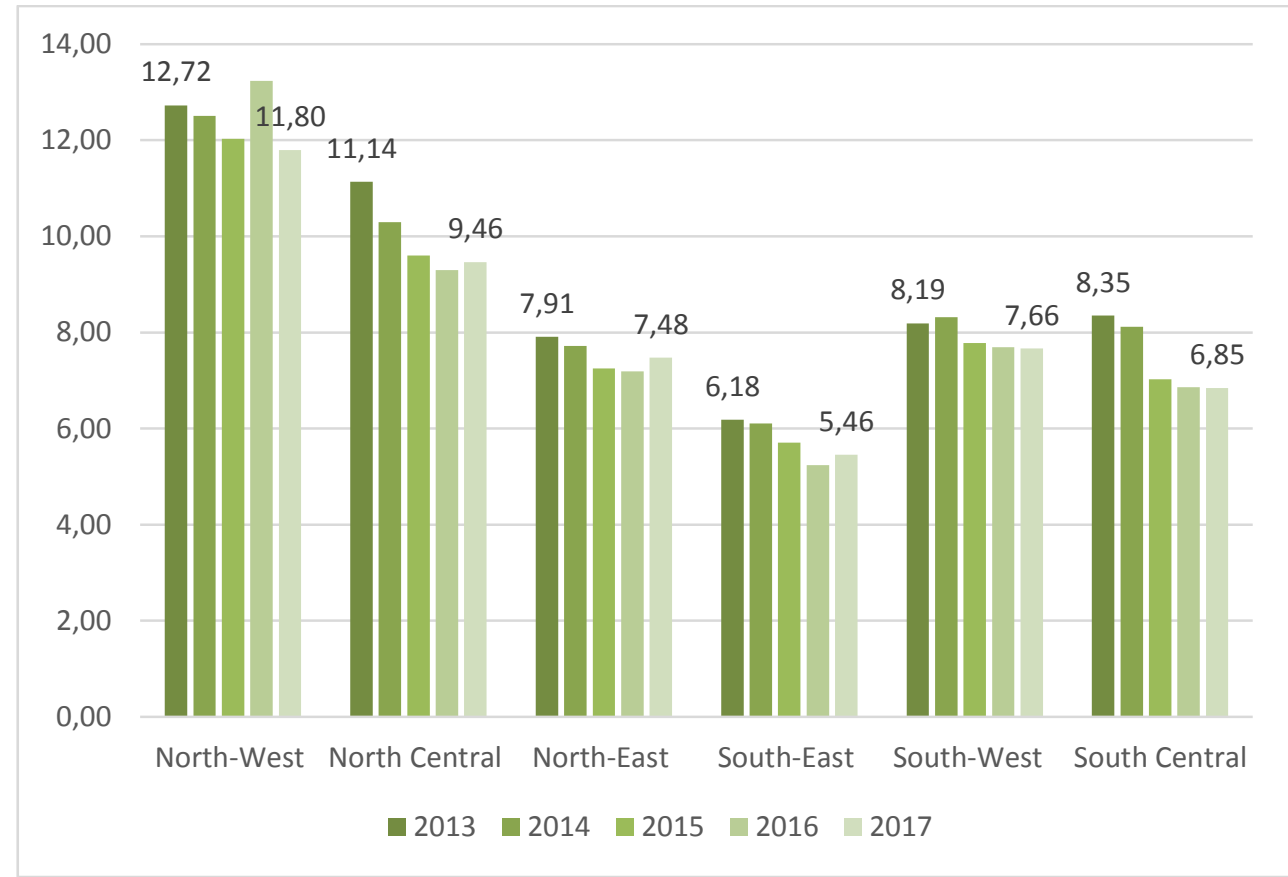

Figure 2. Changes of relative share of agriculture in Gross Value Added (2013-2017)

The differences in the structure of arable land are also significant. The data in Figure $\mathbf{3}$ show that grain crops dominate in all areas, reaching $60 \%$ in the North-East and South-East regions. Oilseeds are in the range of $35.5 \%$ in the Southwest region and $30-31 \%$ in the other four regions. At least $25.1 \%$ is their relative share in the South Central Region.

The Southern Central region is a leader in the area of vegetables (22\%), with a share of $8.3 \%$ against $2.9 \%$ in the North-West region.
In many regions of the country, the number of cultivated crops decreases, with only 4 crops grown over $78-80 \%$ of the arable land during the last 5 years. The trend towards strengthening the monocultural character of agriculture is positively assessed in view of the increasing competitiveness of some productions, but the use of a land for cereals or sunflower creates a 14-15 times lower return than its use for tomato-field production (9).

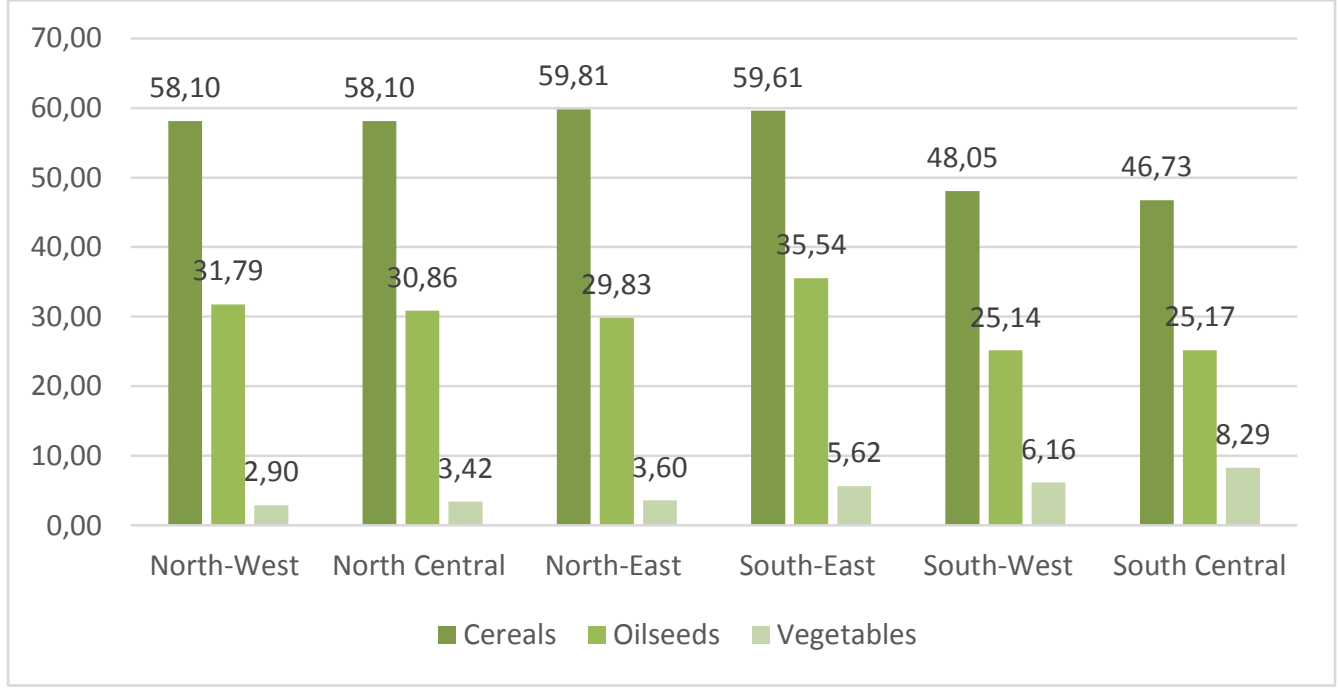

Figure 3. Relative shares of cereals, oilseeds and vegetables in arable land by regions

Moreover, monoculture agriculture leads to a reduction in soil fertility and biodiversity (10), to a reduction of employment in rural areas, and to the intensification of the migration processes of rural population,
The Southern Central Region is a leader in the areas of permanent crops - $27,64 \%$, followed by the Southeastern $-26,62$.

In livestock breeding, there is a stabilization in some and continuing decline in the number of 
other species. For all types of farm animals, in 2017 there is a consolidation of farms. The most significant growth was recorded in the average number of goat grown in a farm - by $39.3 \%$, followed by pigs - by $30.7 \%$, cattle and buffalo respectively by $14 \%$ to 11,5 cows and in buffaloes - by $52.6 \%$, up to 29 pieces (11).

These average herd sizes are significantly lower than those of main EU producers, which is one of the explanations for the low competitiveness of our animal products.

As shown in Table 1, the largest changes took place in the North-West region, where the number of holdings decreased by more than 2.3 times, and the smallest were in the SouthWest and South Central regions where ceased operations respectively $35.7 \%$ and $41.95 \%$ of the farms.
Regional differences in the bred livestock are essential. In the North-East region of the country on average 18.1 animals are bred in a farm, being this region the leader in pig, poultry, sheep and goat farming. In the case of cattle and buffalo, the South-East Planning Region has a leading position with 8 animals on average in a farm and South Central with 5.8 animals in a farm.

\section{CHANGES IN ORGANIZATIONAL STRUCTURES}

Together with the product, there are also significant changes in the number and composition of farms. In just seven years, about 170,000 farms have ceased operations, ie. in 2016 , only $54.3 \%$ of the farms that existed in 2010 continue to work.

Table 1. Changes in the number of farms by regions of the country

\begin{tabular}{|l|r|r|r|r|}
\hline & $2010 \Gamma$. & $2013 \Gamma$. & $2016 \Gamma$. & 54,3 \\
\hline Bulgaria & 370222 & 254142 & 201014 & 43,29 \\
\hline North-West & 51290 & 30381 & 22205 & 52,81 \\
\hline North Central & 43281 & 28633 & 22855 & 51,25 \\
\hline North-East & 43746 & 27999 & 22421 & 48,92 \\
\hline South- East & 56945 & 36755 & 27860 & 64,32 \\
\hline South-West & 65510 & 52082 & 42134 & 58,05 \\
\hline South Central & 109450 & 78292 & 63539 & \\
\hline
\end{tabular}

Source: Ministry of Agriculture, Food and Forestry, department Agrostatistic. 2018

Regional product structures and changes in farm numbers have reflected in the average size of farms. Over the seven-year period, the average size of the used agricultural land increased most in the North-West region, and least in the South Central region.
In 2016 the differences between the average sizes are almost 6 times (Figure 5). Highest is the average size (43.86 ha) of farms in the North-West region, and the lowest is in the South-West and South Central regions - 7.39 ha and 7.96 ha respectively.

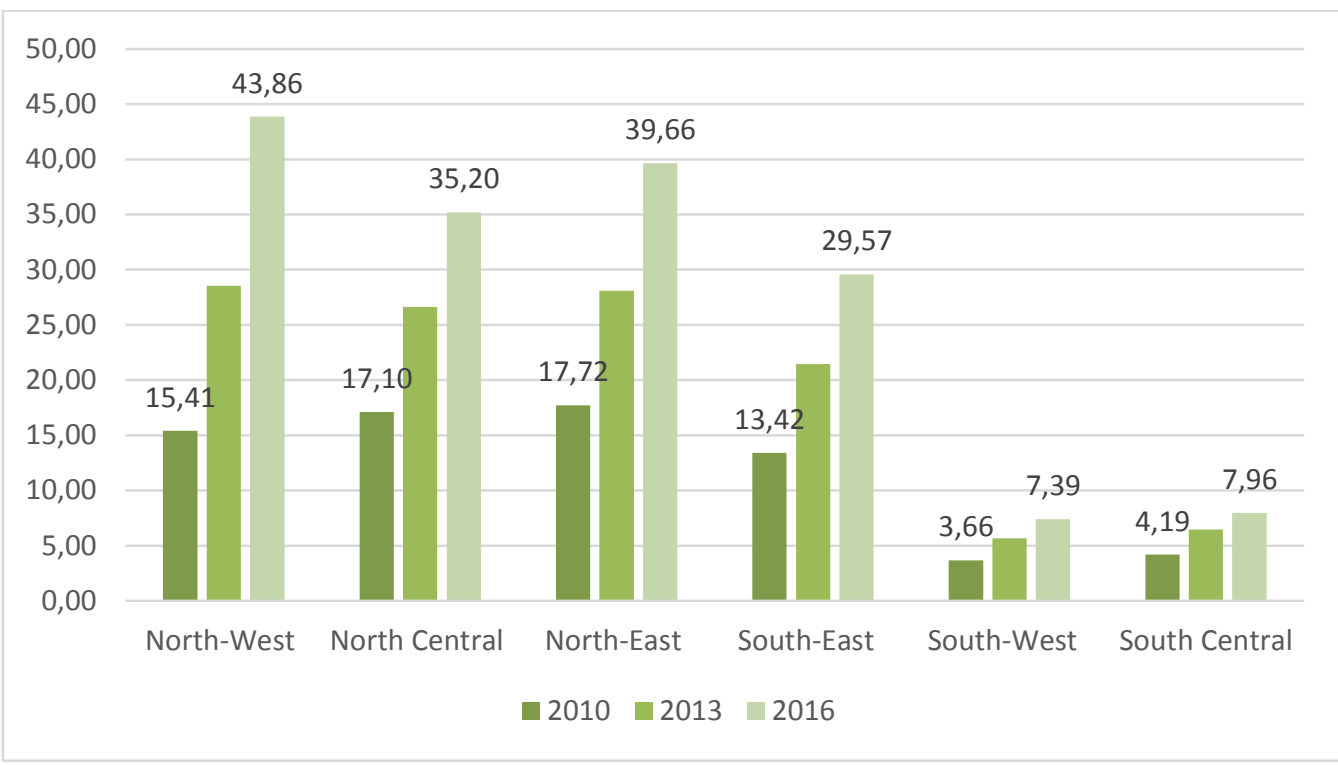

Figure 4. Changes of average size of farms (2010-2016) 
In the latter two areas, the relative share of family farms and family labor is highest. If South-West region had a relative share of family labor of $88.62 \%$, the figures for South Central region are $78.62 \%$ and only $60.76 \%$ in the North-East.

In the South-West region is the highest the relative share of employed in farms over 55 years. They reach $59.08 \%$, while in the NorthEast region they are $35.21 \%$.

\section{RESULTS AND IMPACTS ON RURAL AREAS}

The analyzed differences in the restructuring processes in the six regions show that a different model of agriculture has been formed in each of them. Most of the analyzed features showed similar values between the three northern regions on the one hand, and between Southwestern and South Central regions. Similarities relate both to the speed of changes in the number of farms and their average size, and to the differences in their production structures.
In order to assess the differences in the results of the economic activity, are used the following indicators - net added value of one annual work unit and net income of one annual work unit.

The data from Figure 5 can be taken as results of the application of the regional models of agriculture. The net added value of one annual work unit in the North-East region (BGN 26.5 thousand) is highest, followed by the other two northern regions, respectively the West (23.2 thousand BGN) and the Central one (BGN 22.4 thousand).

This indicator is lowest in the Southwestern and South Central regions, respectively BGN 8.9 thousand and BGN 6.9 thousand.

The differences in net income per annual working unit are smaller, ranging from 6.7 thousand BGN (South Central region) to 9.9 thousand BGN (North-West region).

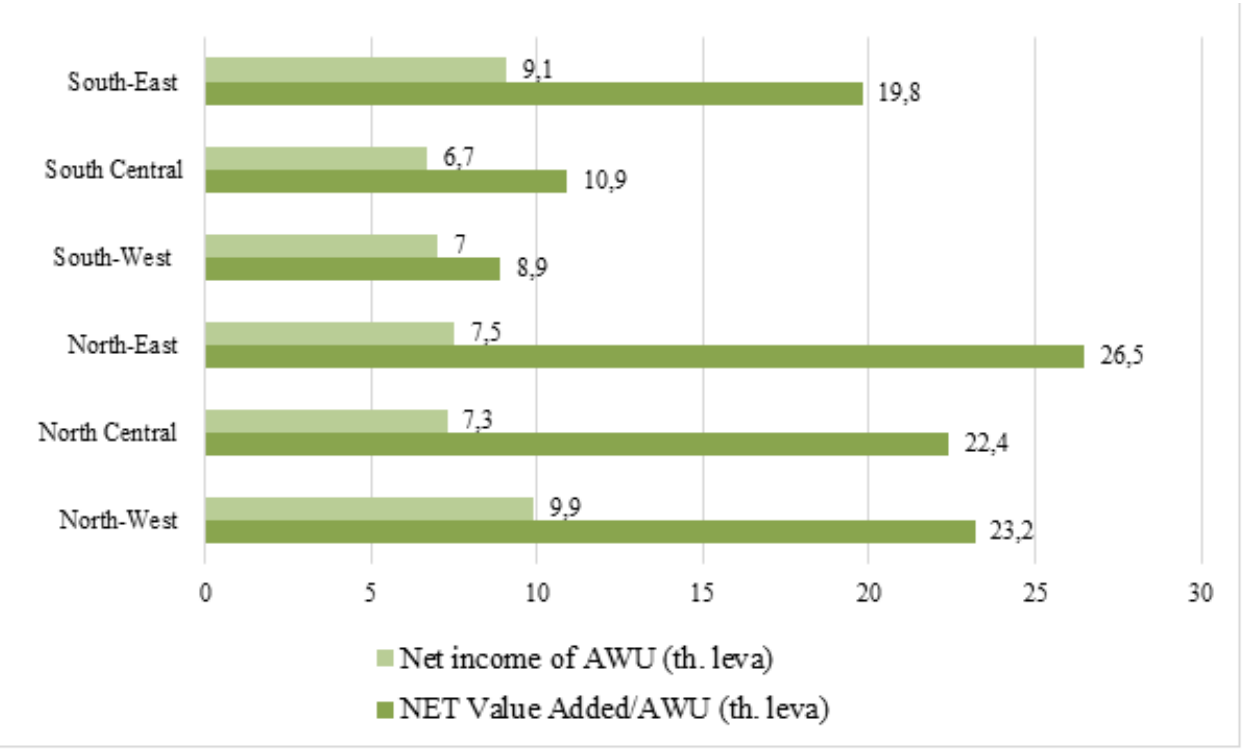

Figure 5.Net value and net income of annual working units

The changes and characteristics of agriculture in northern Bulgaria show that the applied CAP stimulates to a higher degree the development of grain, oil and certain technical crops and contributes to the accelerated concentration of production and competitiveness of the produced products.

At the same time, this is related to the limitation of the type and number of cultivated crops, the liquidation of a significant part of the farms and the workplaces, the deterioration of the impact of the agricultural activity on the environment. Ultimately, this leads to income decrease, increasing unemployment and migration processes to larger cities, district centers and other countries in the world. All this together with the problems of restructuring the local economies are among the main prerequisites for the rapid reduction of the population in the Northwest region by about $20 \%$ during the years of Bulgaria's membership in the EU.

Agricultural characteristics in the Southwest and South Central Regions reveal a model of 
farming with a large number of small (mostly family) farms combining the cultivation of vegetables, perennials, fodder and various animal species. Such specialization results not only in a higher value of the output per unit of agricultural land, but also is a prerequisite for the development of activities which create additional value on the territory of rural areas, ie. for a multifunctional farm. This is where family work is used full-time and the unemployment and migration levels in these areas are lower.

Regional models of agriculture in different regions of the country should be developed successfully on the basis of the establishment of regional programs for adaptation of the national agrarian policy and financing according to the needs of the regions and decentralization of their financing.

\section{ACKNOWLEDGEMENTS}

The research leading to these results has received funding from the Bulgarian Science Fund - project "Sustainable multifunctional rural areas: rethinking agricultural models and systems with increased requirements and limited resources" (2017-2020).

\section{REFERENCES}

1. European Commission, The CAP towards 2020: Meeting the Food, Natural Resources and Territorial Challenges of the Future. COM, Brussels (2010) 672 final, 2010..

2. European Commission, Sustainable Food Consumption and Production in a Resource-constrained World. Standing Committee on Agricultural Research (SCAR), Brussels, 2011.
DOITCHINOVA J.

3. Knickel, K., Agricultural structural change: impact on the rural environment. J. Rural Stud. 6 (4), 383-393, 1990.

4. Knickel, K., Changes in agricultural production and their potential impact on the development of rural areas. Q. J. Int. Agric. 36 (4), 353-378, 1997.

5. Knickel, K., Zemeckis, R., Tisenkopfs, T., A critical reflection of the meaning of agricultural modernization in a world of increasing demands and finite resources. In: Proceedings, vol. 6. ASU Publishing Center, Kaunas, Akademija, pp. 561-567, 2013.

6. Miteva, A., Kanchev, Multifunctional rural development and grape-wine sector organizational structures, in Sustainable agriculture and rural development in terms of the Republic of Serbia strategic goals realization within the Danube region, Belgrade, pp.17-32, 2019.

7. National Statistical Institute, 2019.

8. Ivanov B. at al. Synthesized report. 10 years CAP in Bulgaria, Institute of agricultural economy, Sofia, 2017.

9. Ministry of Agriculture and Foods, Table for calculating the economic size of agricultural holdings for the 2014-2020 programming period, 2013.

10. Harizanova-Bartos H., Stoyanova Z., Impact of agriculture on soil pollution, Economics of Agriculture, Belgrade, No. 2:375-388, 2019.

11. Ministry of Agriculture, Food and Forestry, Agrarian report 2018. 